\title{
IMPROVING THE STRENGTH OF THE AISI 321 AUSTENITIC STAINLESS STEEL BY FRICTIONAL TREATMENT
}

\author{
R. A. Savrai ${ }^{1 *}$, A. V. Makarov ${ }^{1,2}$, I. Yu. Malygina ${ }^{1}$, \\ S. A. Rogovaya ${ }^{1}$, A. L. Osintseva ${ }^{1}$ \\ ${ }^{1}$ Institute of Engineering Science, Ural Branch of the Russian Academy of Sciences, \\ 34 Komsomolskaya St., Ekaterinburg, 620049, Russian Federation \\ ${ }^{2}$ M.N. Miheev Institute of Metal Physics, Ural Branch of the Russian Academy of Sciences, \\ 18 S. Kovalevskoy St., Ekaterinburg, 620990, Russian Federation \\ *Corresponding author. E-mail: ras@imach.uran.ru \\ Address for correspondence: ul. Komsomolskaya, 34, 620049, Ekaterinburg, Russian Federation \\ Tel.: +7 (343) 36234 48; fax: +7 (343) 3745330
}

The influence of frictional treatment on the micromechanical characteristics, phase composition, residual stresses, surface roughness and damage of the AISI 321 austenitic stainless steel is investigated. The frictional treatment is performed with a hemispherical synthetic diamond indenter, loaded with $294 \mathrm{~N}$, in a non-oxidizing argon medium, by varying the number of indenter strokes over the same part of the surface. It has been established that, to achieve substantial hardening, high quality and sufficient contact strength of the steel surface, it is expedient that, with the used process parameters, the frictional treatment of the AISI 321 steel be carried out with the number of double strokes not exceeding 14. Herewith, frictional treatment with 14 double strokes increases microhardness by a factor of 3.7 , up to $730 \mathrm{HV} 0.025$, while providing low surface roughness with $R \mathrm{a}=0.23 \mathrm{~mm}$ and highly increased ability of the surface to resist mechanical contact, this being supported by the data of kinetic microindentation.

Keywords: austenitic stainless steel, frictional treatment, microhardness, kinetic microindentation, phase composition, residual stresses, surface roughness, damage

DOI: $10.17804 / 2410-9908.2017 .5 .043-062$

\section{References}

1. Sun Y. Sliding wear behavior of surface mechanical attrition treated AISI 304 stainless steel. Tribology International, 2013, vol. 57, pp. 67-75. DOI: 10.1016/j.triboint.2012.07.015

2. Lee H., Kim D., Jung J., Pyoun Y., Shin K. Influence of peening on corrosion properties of AISI 304 stainless steel. Corrosion Science, 2009, vol. 51, iss. 12, pp. 2826-2830. DOI: 10.1016/j.corsci.2009.08.008

3. Mordyuk B.N., Prokopenko G.I. Ultrasonic impact peening for the surface properties' management. Journal of Sound and Vibration, 2007, vol. 308, iss. 3-5, pp. 855-866. DOI: $10.1016 /$ j.jsv.2007.03.054

4. Baraz V.P., Kartak B.P., Mineeva O.N. Special features of friction hardening of austenitic steel with unstable gamma-phase. Metal Science and Heat Treatment, 2011, vol. 52, iss. 9-10, pp. 473-475. DOI: 10.1007/s11041-010-9302-x

5. Hajian M., Abdollah-zadeh A., Rezaei-Nejad S.S., Assadi H., Hadavi S.M.M., Chung K., Shokouhimehr M. Improvement in cavitation erosion resistance of AISI 316L stainless steel by friction stir processing. Applied Surface Science, 2014, vol. 308, pp. 184-192. DOI: 10.1016/j.apsusc.2014.04.132

6. $\quad$ Lin Y., Wang J., Zeng D., Huang R., Fan H. Advance complex liquid nitriding of stainless steel AISI 321 surface at 430 C. Journal of Materials Engineering and Performance, 2013, vol. 22, no. 9 , pp. 2567-2573. DOI: $10.1007 / \mathrm{s} 11665-013-0545-8$ 
7. Levcovici S.M., Levcovici D.T., Munteanu V., Paraschiv M.M., Preda A. Laser surface hardening of austenitic stainless steel. Journal of Materials Engineering and Performance, 2000, vol. 9, no. 5, pp. 536-540. DOI: 10.1361/105994900770345665

8. Golzar Shahri M., Salehi M., Hosseini S.R., Naderi M. Effect of nanostructured grains on martensite formation during plasma nitriding of AISI 321 austenitic stainless steel. Surface and Coatings Technology, 2017, vol. 310, pp. 231-238. DOI: 10.1016/j.surfcoat.2016.12.019

9. Makarov A.V. Nanostructuring friction treatment of carbon and low-alloy steels. In: Perspektivnye Materialy. T. IV: Uchebnoe posobie [Promising Materials, vol. IV: Schoolbook], D.L. Merson, ed., Tolyatti, TGU Publ., 2011, 434 p. (In Russian).

10. Makarov A.V., Skorynina P.A., Osintseva A.L., Yurovskikh A.S., Savrai R.A. Improving the tribological properties of austenitic $12 \mathrm{Kh} 18 \mathrm{~N} 10 \mathrm{~T}$ steel by nanostructuring frictional treatment. Obrabotka Metallov, 2015, no. 4 (69), pp. 80-92. DOI: 10.17212/1994-6309-2015-4-80-92 (In Russian).

11. Makarov A.V., Korshunov L.G. Strength and wear resistance of nanocrystal structures on friction surfaces of steels with martensitic base. Russian Physics Journal, 2004, vol. 47, no. 8, pp. 857-871. DOI: 10.1007/s11182-005-0005-5

12. Wang T.S., Yang J., Shang C.J., Li X.Y, Lv B., Zhang M., Zhang F.C. Sliding friction surface microstructure and wear resistance of $9 \mathrm{SiCr}$ steel with low-temperature austempering treatment. Surface and Coatings Technology, 2008, vol. 202, iss. 16, pp. 4036-4040. DOI: 10.1016/j.surfcoat.2008.02.013

13. Li J.G., Umemoto M., Todaka Y., Tsuchiya K. Role of strain gradient on the formation of nanocrystalline structure produced by severe plastic deformation. Journal of Alloys and Compounds, 2007, vol. 434-435, pp. 290-293. DOI: 10.1016/j.jallcom.2006.08.167

14. Makarov A.V., Savrai R.A., Pozdejeva N.A., Smirnov S.V., Vichuzhanin D.I., Korshunov L.G., Malygina I.Yu. Effect of hardening friction treatment with hard-alloy indenter on microstructure, mechanical properties, and deformation and fracture features of constructional steel under static and cyclic tension. Surface and Coatings Technology, 2010, vol. 205, iss. 3, pp. 841-852. DOI: 10.1016/j.surfcoat.2010.08.025

15. Vychuzhanin D.I., Makarov A.V., Smirnov S.V., Pozdeeva N.A., Malygina I.Y. Stress and strain and damage during frictional strengthening treatment of flat steel surface with a sliding cylindrical indenter. Journal of Machinery Manufacture and Reliability, 2011, vol. 40, iss. 6, pp. 554-560. DOI: 10.3103/S1052618811050190

16. Kuznetsov V.P., Makarov A.V., Psakhie S.G., Savrai R.A., Malygina I.Yu., Davydova N.A. Tribological aspects in nanostructuring burnishing of structural steels. Physical Mesomechanics, 2014, vol. 17, iss. 4, pp. 250-264. DOI: 10.1134/S102995991404002X

17. Makarov A.V., Skorynina P.A., Yurovskikh A.S., Osintseva A.L. Effect of the technological conditions of frictional treatment on the structure, phase composition and hardening of metastable austenitic steel. In: AIP Conference Proceedings, 2016, vol. 1785, no. 040035. DOI: 10.1063/1.4967092

18. Wang T., Yu J., Dong B. Surface nanocrystallization induced by shot peening and its effect on corrosion resistance of 1Cr18Ni9Ti stainless steel. Surface and Coatings Technology, 2006, vol. 200, pp. 4777-4781. DOI: 10.1016/j.surfcoat.2005.04.046

19. Pugacheva N.B., Michurov N.S., Bykova T.M. structure and properties of the Al/SiC composite material. The Physics of Metals and Metallography, 2016, vol. 117, no. 6, pp. 634-640. DOI: $10.1134 / \mathrm{S} 0031918 X 16060119$

20. Pugacheva N.B., Michurov N.S., Senaeva E.I., Bykova T.M. Structure and thermophysical properties of aluminum-matrix composites. The Physics of Metals and Metallography, 2016, vol. 117, no. 11, pp. 1144-1151. DOI: 10.1134/S0031918X16110119

21. Savrai R.A., Makarov A.V., Soboleva N.N., Malygina I.Yu., Osintseva A.L. The behavior of gas powder laser clad NiCrBSi coatings under contact loading. Journal of Materials Engineering and Performance, 2016, vol. 25, iss. 3, pp. 1068-1075. DOI: 10.1007/s11665-016-1925-7 
22. Pugacheva N.B., Trushina E.B., Bykova T.M. Research on the tribological properties of iron borides as diffusion coatings. Journal of Friction and Wear, 2014, vol. 35, no. 6, pp. 489-496. DOI: $10.3103 /$ S1068366614060117

23. Pugacheva N.B., Bykova T.M., Trushina E.B. Effect of the composition of the steel base on the structure and properties of diffusion boride coatings. Uprochnyayushchie Tekhnologii i Pokrytiya, 2013, no. 4, pp. 3-7. (In Russian).

24. Makarov A.V., Savrai R.A., Gorkunov E.S., Yurovskikh A.S., Malygina I.Yu., Davydova N.A. Structure, mechanical characteristics, and deformation and fracture features of quenched structural steel under static and cyclic loading after combined strain-heat nanostructuring treatment. Physical Mesomechanics, 2015, vol. 18, iss. 1, pp. 43-57. DOI: 10.1134/S1029959915010063

25. Makarov A.V., Soboleva N.N., Savrai R.A., Malygina I.Yu. The improvement of micromechanical properties and wear resistance of chrome-nickel laser coating using the finishing friction treatment. Science Vector of Togliatti State University, 2015, no. 4 (34), pp. 60-67. DOI: 10.18323/2073-5073-2015-4-60-67 (In Russian).

26. Smirnov S.V., Pugacheva N.B., Myasnikova M.V., Smirnova E.O. Heterogeneity of an Al alloy weld and simulation of its elastic deformation. Fizicheskaya Mezomekhanika, 2014, no. 1, pp. 51-56. (In Russian).

27. Smirnov S.V., Pugacheva N.B., Myasnikova M.V. Evaluating ultimate strains to fracture of the zones of a diffusion aluminide coating. Deformatsiya $i$ Razrushenie Materialov, 2014, no. 12, pp. 17-22. (In Russian).

28. Pugacheva N.B., Myasnikova M.V., Michurov N.S. Simulation of the elastic deformation of laser-welded joints of an austenitic corrosion-resistant steel and a titanium alloy with an intermediate copper insert. The Physics of Metals and Metallography, 2016, vol. 117, no. 2, pp. 195-203. DOI: $10.7868 / \mathrm{S} 0015323015120074$

29. Makarov A.V., Korshunov L.G., Osintseva A.L. Sposob Obrabotki Stalnykh Izdeliy [Method for Steel Articles Working]. RU Patent 2194773, 2002. (In Russian).

30. Rusakov A.A. Rentgenografiya Metallov [Roentgenography of Metals]. Moscow, Atomizdat Publ., 1977, 480p. (In Russian).

31. ISO 14577-1:2015. Metallic materials. Instrumented indentation test for hardness and materials parameters. Part 1: Test method.

32. Oliver W.C., Pharr J.M. An improved technique for determining hardness and elastic modulus using load and displacement sensing indentation experiments. Journal of Materials Research, 1992, vol. 7, no. 6, pp. 1564-1583. DOI:10.1557/JMR.1992.1564

33. Makarov A.V., Savrai R.A., Schastlivtsev V.M., Tabatchikova T.I., Yakovleva I.L., Egorova L.Yu. Structural features of the behavior of a high-carbon pearlitic steel upon cyclic loading. The Physics of Metals and Metallography, 2011, vol. 111, iss. 1, pp. 95-109. DOI: 10.1134/S0031918X11010091

34. Benito J.A., Jorba J., Manero J.M., Roca A. Change of Young's modulus of cold-deformed pure iron in a tensile test. Metallurgical and Materials Transactions A, 2005, vol. 36, iss. 12, pp. 3317-3324. DOI: 10.1007/s11661-005-0006-6

35. Cheng Y.T., Cheng C.M. Relationships between hardness, elastic modulus and the work of indentation. Applied Physics Letters, 1998, vol. 73, no. 5, pp. 614-618. DOI: 10.1063/1.121873

36. Page T.F., Hainsworth S.V. Using nanoindentation techniques for the characterization of coated systems: a critique. Surface and Coatings Technology, 1993, vol. 61, iss. 1-3, pp. 201-208. DOI: 10.1016/0257-8972(93)90226-E

37. Mayrhofer P.H., Mitterer C., Musil J. Structure-property relationships in single- and dualphase nanocrystalline hard coatings. Surface and Coatings Technology, 2003, vol. 174-175, pp. 725-731. DOI: 10.1016/S0257-8972(03)00576-0

38. Milman Yu.V., Chugunova S.I., Goncharova I.V. Plasticity characteristic defined indentation method. Voprosy atomnoy nauki i tekhniki, 2011, iss. 4, pp. 182-187. (In Russian). 
This work was done within the Complex program of UB RAS, project no. 15-10-1-22, within the state order of FASO Russia on the subject "Structure" no. 01201463331 and with partial financial support of the Russian Foundation for Basic Research grant no. 15-08-06754_a.

Electron scanning microscopy, optical profilometry and micromechanical tests were performed in Collective Use Center "Plastometriya" of the Institute of Engineering Science UB RAS. 
Подана в журнал: 10.10 .2017

УДК 669.14:621.787.4

DOI: $10.17804 / 2410-9908.2017 .5 .043-062$

\title{
ПОВЫШЕНИЕ ПРОЧНОСТИ КОРРОЗИОННОСТОЙКОЙ АУСТЕНИТНОЙ СТАЛИ AISI 321 ФРИКЦИОННОЙ ОБРАБОТКОЙ
}

\author{
Р. А. Саврай ${ }^{1 *}$, А. В. Макаров ${ }^{1,2}$, И. Ю. Малыгина ${ }^{1}$, \\ С. А. Роговая ${ }^{1}$, А. Л. Осинцева ${ }^{1}$ \\ ${ }^{1}$ Федеральное государственное бюджетное учреждение науки \\ Институт машиноведения Уральского отделения Российской академии наук, \\ д. 34, ул. Комсомольская, г. Екатеринбург, 620049, Российская Федерация \\ ${ }^{2}$ Федеральное государственное бюджетное учреждение науки \\ Институт физики металлов имени М.Н. Михеева Уральского отделения Российской академии наук, \\ д. 18, ул. С. Ковалевской, г. Екатеринбург, 620990, Российская Федерация \\ *Ответственный автор. Электронная почта: ras@imach.uran.ru \\ Адрес для переписки: ул. Комсомольская, 34, Екатеринбург, Российская Федерация \\ Тел.: +7 (343) 362-34-48; факс: +7 (343) 374-53-30
}

Исследовано влияние фрикционной обработки полусферическим индентором из синтетического алмаза в безокислительной среде аргона и нагрузке на индентор 294 Н с различным числом проходов индентора по одному участку поверхности на микромеханические характеристики, фазовый состав, остаточные напряжения, шероховатость и поврежденность поверхностного слоя коррозионностойкой аустенитной стали AISI 321. Установлено, что для обеспечения существенного упрочнения, высокого качества поверхности и стойкости при контактных нагрузках, фрикционную обработку стали AISI 321 при использованных технологических параметрах целесообразно проводить с числом двойных проходов не более 14 . При этом в результате фрикционной обработки с числом двойных проходов индентора 14, микротвердость стали AISI 321 возрастает в 3,7 раза до 730 HV0,025, обеспечивается низкая шероховатость поверхности с параметром $R \mathrm{a}=0,23$ мкм, а также значительно повышается способность поверхности сопротивляться механическому контактному воздействию, что подтверждается данными микроиндентирования.

Ключевые слова: коррозионностойкая аустенитная сталь, фрикционная обработка, микротвердость, кинетическое микроиндентирование, фазовый состав, остаточные напряжения, шероховатость поверхности, поврежденность.

\section{1. Введение}

Аустенитные хромоникелевые стали обладают высокой технологичностью и коррозионной стойкостью. Благодаря этому они находят широкое применение в нефтегазовой, химической, пищевой и других отраслях промышленности. Однако этим сталям свойственны низкие прочностные свойства и склонность к схватыванию, которые могут быть устранены различными поверхностными модифицирующими обработками [1-8].

В частности, эффективным способом упрочнения и наноструктурирования поверхностного слоя металлических изделий является фрикционная обработка, проводимая в условиях трения скольжения, исключающих заметный фрикционный нагрев обрабатываемой поверхности [9]. При фрикционной обработке в результате интенсивной пластической деформации на поверхности практически любых металлических материалов, включая высокопрочные и труднодеформируемые термоупрочненные стали, формируются нанокристаллические структуры с уникальными прочностными и трибологическими характеристиками [10-12]. 
Фрикционная обработка имеет следующие основные научно-технологические аспекты. Важнейшим условием формирования нанокристаллических структур в металлических материалах при интенсивной пластической деформации является негомогенная деформация сдвигом с наличием резкого градиента [13]. В работах $[14,15]$ было показано, что именно сдвиговая компонента деформации вносит определяющий вклад в накопление пластической деформации (и соответственно в деформационное упрочнение) металла при контактном фрикционном воздействии.

Для формирования качественной поверхности при фрикционной обработке также необходим обоснованный выбор материала индентора, который должен исключать адгезионное схватывание и разрушение поверхности, обеспечивая при этом достаточно высокий коэффициент трения для накопления деформации. В качестве материала индентора могут быть использованы такие сверхтвердые материалы, как твердый сплав, природный и синтетический алмаз, плотный нитрид бора [16]. Для аустенитных нержавеющих сталей, при фрикционной обработке наиболее эффективно использование индентора из синтетического алмаза [17].

При контактном нагружении в воздушной среде происходит активное насыщение кислородом нанокристаллических структур трения, обусловленное их высокой дефектностью (большая плотность дислокаций, сильно развитая система границ фрагментов), а также действием ротационного механизма пластической деформации, способствующего ускоренной транспортировке атомов (ионов) кислорода с контактной поверхности в объем материала. Обогащение кислородом сильнодеформированного поверхностного слоя увеличивает его хрупкость и приводит к ускоренному разрушению [11]. Поэтому деформационная поверхностная обработка в окислительной среде воздуха вследствие охрупчивания поверхностных слоев из-за механохимического взаимодействия металла с кислородом воздуха может приводить к шелушению и отслаиванию упрочненного слоя, а также усиленному износу деформирующего инструмента, который также охрупчивается при контакте с кислородом. При этом безокислительная среда обработки (например инертный газ) обеспечивает накопление максимальных степеней пластической деформации и формирование нанокристаллических структур в возможно более толстом поверхностном слое.

Поскольку аустенитные стали типа X18Н10T характеризуются деформационной нестабильностью, важным также является вопрос влияния поверхностных обработок на коррозионную стойкость. В работе [18] показано, что при поверхностной пластической деформации стали $1 \mathrm{Cr} 18 \mathrm{Ni9Ti} \mathrm{не} \mathrm{происходит} \mathrm{ухудшения} \mathrm{её} \mathrm{коррозионных} \mathrm{свойств.} \mathrm{Это} \mathrm{может} \mathrm{быть} \mathrm{обусловлено}$ сильным диспергированием структуры и изменением электрохимических свойств деформированного поверхностного слоя. Следует отметить, что в настоящее время данный вопрос недостаточно рассмотрен в научной литературе и требует дополнительных исследований.

Для оценки прочности, пластичности и способности поверхностного слоя выдерживать контактные нагрузки могут быть эффективно использованы механические характеристики, определяемые при инструментальном индентировании. Метод кинетического микроиндентирования успешно применяется для определения механических свойств композитных материалов [19, 20], различных покрытий, состав и свойства которых существенно отличаются от таковых для основного металла [21-23], а также для материалов, поверхность которых подвергнута различным упрочняющим обработкам, в том числе, фрикционной обработке [24, 25]. Полученные методом кинетического микроиндентирования характеристики используются при определении напряженно-деформированного состояния материала и прогнозирования развития процессов поврежденности в условиях высоких нагрузок и напряжений [26-28].

Интенсивная пластическая деформация поверхностных слоев материала в процессе фрикционной обработки может сопровождаться образованием микродефектов разрушения (поврежденности) в виде микропор и микротрещин, которые на определенной стадии развития приводят к появлению разрушающей трещины $[14,15]$. Поэтому цель данной работы определение научно-обоснованных параметров фрикционной обработки стали AISI 321 для обеспечения существенного упрочнения, высокого качества поверхности и стойкости при контактных нагрузках. 


\section{2. Материал и методика эксперимента}

Исследовали коррозионностойкую аустенитную сталь AISI 321 промышленной плавки состава (мас. \%): 0,05 C; 16,80 Cr; 8,44 Ni; 0,33 Ti; 1,15 Mn; 0,67 Si; 0,26 Mo; 0,13 Co; $0,03 \mathrm{Nb} ; 0,31 \mathrm{Cu} ; 0,036 \mathrm{P} ; 0,005 \mathrm{~S}$; остальное $\mathrm{Fe}$. В состоянии поставки сталь представляла собой прокатанный лист толщиной 10 мм.

Образцы для фрикционной обработки изготавливали в виде пластин размерами $40 \times 40$ мм. Термическую обработку (закалку) подготовленных образцов из стали AISI 321 проводили по следующему режиму: нагрев до температуры $1100{ }^{\circ} \mathrm{C}$, выдержка при этой температуре в течение 40 мин, охлаждение в воду. Поверхность образцов готовили с помощью механической шлифовки на абразивных шкурках (электрокорунд марки 14A16 зернистостью 160 мкм и марки 64СМ63СП зернистостью 64 мкм) и последующей полировки на алмазных пастах (зернистостью 60/40 мкм; 40/28 мкм; 28/20 мкм; 20/14 мкм; 14/10 мкм; 10/7 мкм и 7/5 мкм) до достижения зеркальной поверхности. После механической полировки, поверхность образцов дополнительно электрополировали в серно-фосфорном электролите состава 100 г $\mathrm{H}_{2} \mathrm{SO}_{4}+400$ г $\mathrm{H}_{3} \mathrm{PO}_{4}+50$ г $\mathrm{CrO}_{3}$ (ангидрид) при температуре $60-70{ }^{\circ} \mathrm{C}$ и плотности тока $1,4-1,5 \mathrm{~A} / \mathrm{cm}^{2}$.

Фрикционную обработку осуществляли в безокислительной среде аргона при сканировании поверхности подготовленных плоских образцов полусферическим индентором из синтетического алмаза с радиусом полусферы 3 мм при нормальной нагрузке на индентор $P=294 \mathrm{H}$, длиной прохода индентора 15 мм и средней скорости скольжения 0,022 м/с (рис. 1). Число двойных проходов индентора по одному участку поверхности $p$ варьировали от 2 до 160 . При $p=2,8,10,12$ и 14 обработку проводили без поперечного смещения индентора и формировали участки шириной 1,6 мм (ширина деформационного следа, оставляемого индентором на поверхности образца). При $p=16$ обработку проводили с поперечным смещением 0,1 мм после каждого двойного прохода индентора и формировали участки шириной 10 мм для структурных исследований. Число двойных проходов индентора р при обработке со смещением определяли как частное от деления ширины деформационного следа на величину поперечного смещения индентора. При $p=48,96,112$ и 160 обработку проводили с теми же параметрами, что и при $p=16$, многократно сканируя обработанный участок поверхности с числом сканирований 3, 6, 7 и 10 соответственно. Данная обработка соответствует авторскому способу обработки стальных изделий при скольжении инденторами из твердых и сверхтвердых материалов при скоростях и нагрузках, исключающих заметный фрикционный нагрев поверхности [29]. В про-

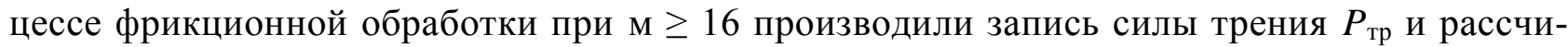
тывали коэффициент трения $f\left(f=P_{\text {тр }} / P\right)$.

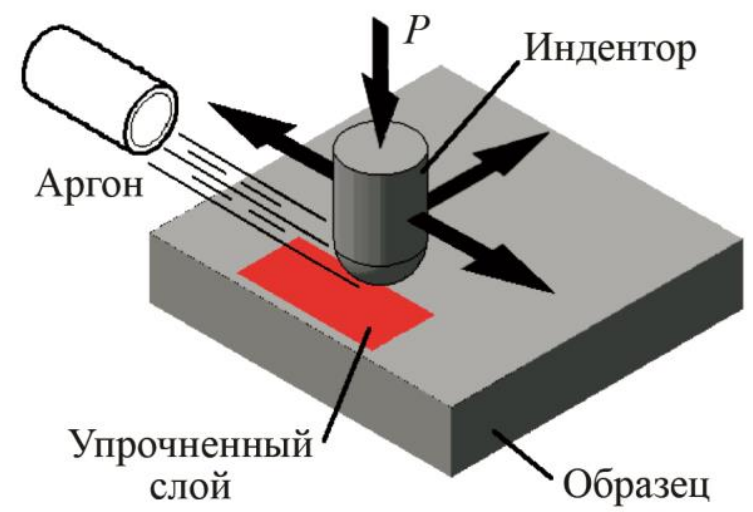

Рис. 1. Схема фрикционной обработки полусферическим индентором 
Поверхности образцов после фрикционной обработки изучали методом сканирующей электронной микроскопии (СЭМ) с применением микроскопа Tescan VEGA II XMU. Параметры шероховатости поверхности образцов определяли с помощью оптического профилометра Wyko NT-1100. Рентгеноструктурное исследование выполняли на дифрактометре Shimadzu XRD-7000 в CrK $\alpha^{-}$-излучении. Определяли фазовый состав и остаточные напряжения в $\alpha$-фазе $\sigma_{\alpha}$ для чего использовали метод наклонной съемки [30].

Микротвердость по методу восстановленного отпечатка определяли на приборе Shimadzu HMV-G21DT при нагрузке 0,245 H, скорости нагружения 40 мкм/с и выдержке под нагрузкой 15 с. Кинетическое микроиндентирование с записью диаграммы нагружения проводили на измерительной системе Fischerscope HМ2000 XYm с использованием индентора Виккерса и программного обеспечения WIN-HCU при максимальной нагрузке 0,245 Н, времени нагружения 20 с, выдержке при нагрузке 15 с и времени разгрузки 20 с (рис. 2). Согласно стандарту ISO 14577 [31] определяли максимальную глубину вдавливания индентора $h_{\max }$ и остаточную глубину вдавливания индентора после снятия нагрузки $\mathrm{h}_{\mathrm{p}}$, контактный модуль упругости $E^{*}\left(E^{*}=E /\left(1-v^{2}\right)\right.$, где $E-$ модуль Юнга; $v$ - коэффициент Пуассона), твердость вдавливания при максимальной нагрузке $H_{\mathrm{IT}}$, твердость по Мартенсу НM, работу обратной упругой деформации вдавливания $W_{\mathrm{e}}$ и общую механическую работу вдавливания $W_{\mathrm{t}}\left(W_{\mathrm{t}}=W_{\mathrm{e}}+W_{\text {о.ф. }}\right)$ (рис. 2$)$. Погрешность характеристик микротвердости и микроиндентирования по 10 измерениям определяли с доверительной вероятностью $p=0,95$.

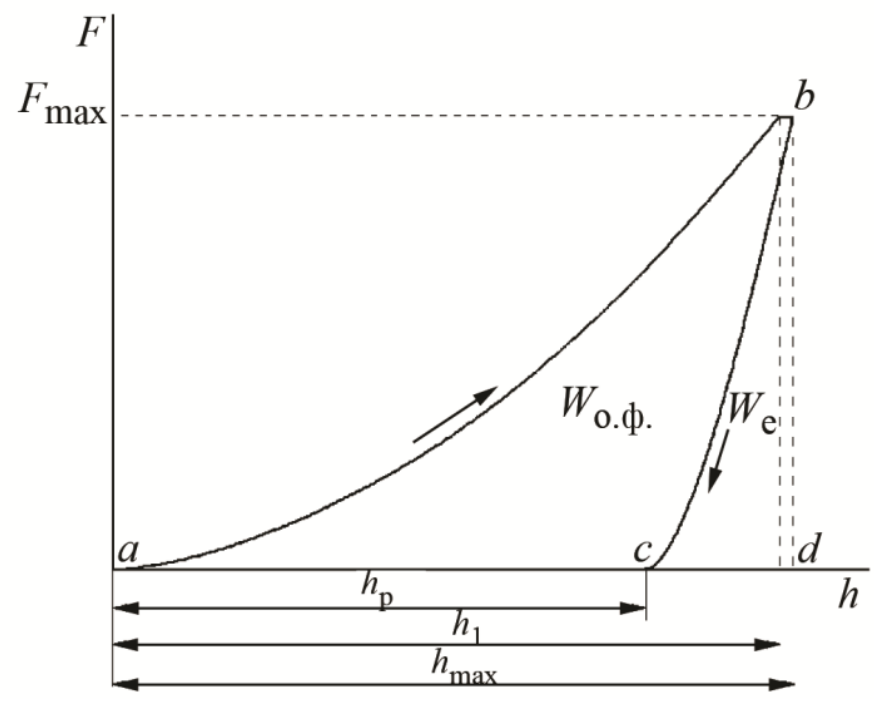

Рис. 2. Диаграмма индентирования. $F$ - нагрузка на индентор; $h$ - глубина внедрения индентора; $a \rightarrow b-$ участок нагружения; $b \rightarrow c-$ участок разгружения; $F_{\max }-$ максимальная нагрузка; $h_{\max }$ - максимальная глубина вдавливания индентора; $h_{\mathrm{p}}$ - остаточная глубина вдавливания индентора после снятия нагрузки; $h_{1}$ - глубина внедрения индентора, соответствующая начальной точке горизонтального участка; $W_{\text {о.ф. }}-$ работа сил остаточного формоизменения, соответствует площади участка под кривой $a b c ; W_{\mathrm{e}}$ - работа обратной упругой деформации вдавливания, соответствует площади участка под кривой $c b d$ 


\section{3 Экспериментальные результаты и их обсуждение}

На рис. 3 а представлена микроструктура стали AISI 321 после термической обработки. Она состоит из аустенитных зерен ( $\gamma$-фазы) и отдельных включений карбида титана ТіС. Поверхность стали AISI 321 характеризуется типичным для электрополированной поверхности сглаженным рельефом с ямками травления (рис. 3 б) и имеет параметры шероховатости: $R \mathrm{a}=0,09$ мкм; $R \mathrm{z}=2,23$ мкм.

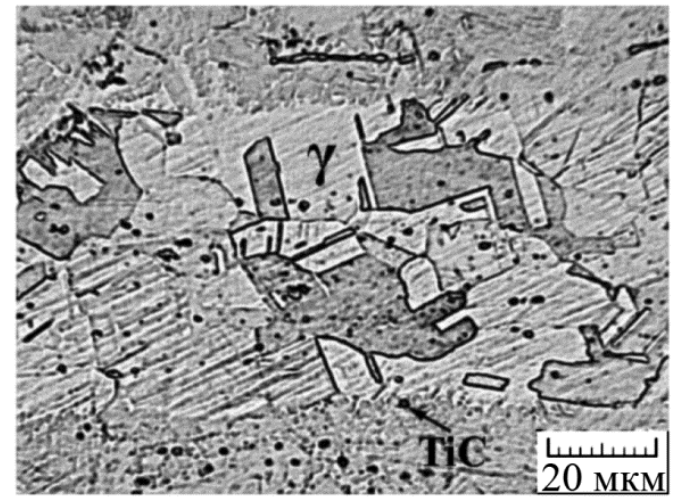

$a$

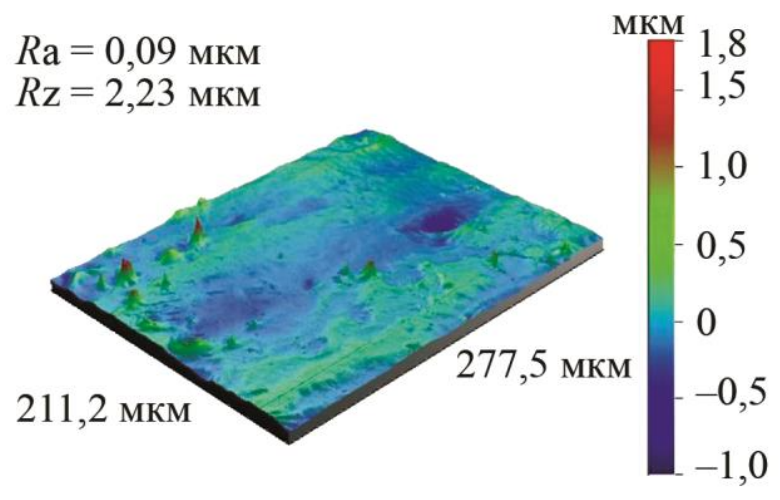

$\sigma$

Рис. 3. Микроструктура ( $a$ ) и вид поверхности (оптическая профилометрия) перед фрикционной обработкой (б) стали AISI 321

В табл. 1 и на рис. 4 и 5 представлены результаты о состоянии поверхности аустенитной стали AISI 321 после фрикционной обработки. Видно, что при увеличении числа двойных проходов индентора от 2 до 14 не наблюдается признаков разрушения поверхности стали AISI 321 (рис. 4 a). Первые отдельные трещины на обработанной поверхности стали AISI 321 появляются при 16 двойных проходах (табл. 1). Дальнейшее увеличение числа двойных проходов до 48 и более приводит к росту количества и протяженности трещин (рис. 4 б-г, указаны стрелками 1), выкрашиванию материала с поверхности образца на некоторых участках (рис. 4 в, г, указаны стрелками 2) и формированию характерных ступенек (рис. 5 в, г). Разрушение поверхности также сопровождается ростом коэффициента трения от 0,39 до 0,52 (табл. 1) и шероховатости поверхности от $R \mathrm{a}=0,23$ мкм, $R \mathrm{z}=2,18$ мкм при 14 двойных проходах индентора до $R \mathrm{a}=1,64$ мкм, $R z=13,24$ мкм при 160 двойных проходах (рис. 5).

Таким образом, для формирования качественной поверхности с низкой шероховатостью и без трещин фрикционную обработку коррозионностойкой аустенитной стали AISI 321 при использованных технологических параметрах следует проводить с числом двойных проходов индентора не более 14.

На рис. 6 представлены данные о влиянии числа двойных проходов индентора р при фрикционной обработке на микротвердость $\mathrm{HV} 0,025$, количество мартенсита деформации $\mathrm{V}_{\alpha}$ и остаточные напряжения в б-фазе уб в поверхностном слое стали AISI 321. Видно, что изменение микротвердости наиболее интенсивно происходит на начальном участке фрикционного нагружения: уже при двух двойных проходах индентора она достигает 375 HV0,025, при 14 проходах возрастает до $730 \mathrm{HV} 0,025$, а при 16 проходах, когда появляются первые трещины, возрастает до $740 \mathrm{HV} 0,025$ (рис. 6 a). При 48 двойных проходах микротвердость достигает максимального значения, равного 865 HV0,025. Максимальный уровень микротвердости сохраняется при фрикционной обработке с числом двойных проходов индентора до 112, после чего наблюдается некоторое снижение микротвердости до 750 HV0,025 при 160 двойных проходах. 
Таблица 1 - Влияние числа двойных проходов индентора р при фрикционной обработке на состояние поверхности и коэффициент трения $f$ стали AISI 321

\begin{tabular}{|c|c|c|}
\hline $\begin{array}{c}\text { Число двойных } \\
\text { проходов индентора } \mathrm{p}\end{array}$ & Состояние поверхности & Коэффициент трения $f$ \\
\hline 2 & Признаки разрушения отсутствуют & - \\
\hline 8 & $-\ll-$ & - \\
\hline 10 & $-\ll-$ & - \\
\hline 12 & $-\ll-$ & - \\
\hline 14 & $-\ll-$ & 0,39 \\
\hline 16 & Отдельные трещины & 0,49 \\
\hline 48 & $-\ll-$ & 0,51 \\
\hline 96 & Многочисленные трещины, участки & 0,51 \\
\hline 112 & с выкрашиванием & 0,52 \\
\hline 160 & $-\ll-$ & \\
\hline
\end{tabular}

В процессе фрикционной обработки в поверхностном слое стали AISI 321 происходит непрерывный рост количества мартенсита деформации $\mathrm{V}_{\alpha}$, которое достигает практически 100 \% при 160 двойных проходах индентора (рис. 6 б).

Фрикционная обработка также способствует формированию остаточных напряжений сжатия в поверхностном упрочненном слое (рис. 6 в). При 16 двойных проходах индентора остаточные напряжения в $\alpha$-фазе $\sigma_{\alpha}$ составляют - 380 МПа. Максимального уровня, равного -515 МПа, остаточные напряжения достигают при 96 двойных проходах. Дальнейшее увеличение числа двойных проходов приводит к снижению уровня остаточных напряжений и для 160 двойных проходов остаточные напряжения составляют порядка - 380 МПа (рис. 6 в).

Наблюдаемый характер изменения микротвердости (рис. 6 a) обусловлен накоплением деформации в поверхностном слое с одновременным увеличением толщины упрочненного слоя, увеличением количества мартенсита деформации (рис. 6 б) и измельчением структуры поверхностного слоя до субмикро- и нанокристаллического состояния $[10,17]$. Уменьшение микротвердости при фрикционной обработке с числом двойных проходов индентора более 112 вызвано развитием процесса разрушения поверхности (табл. 1; рис. 4 в-г; 5 в-г) и, как следствие, уменьшением толщины деформированного упрочненного слоя. Об интенсивном разрушении поверхности при фрикционной обработке с числом двойных проходов 112 и более также свидетельствует снижение уровня остаточных напряжений сжатия в поверхностном слое (рис. 6 в). 


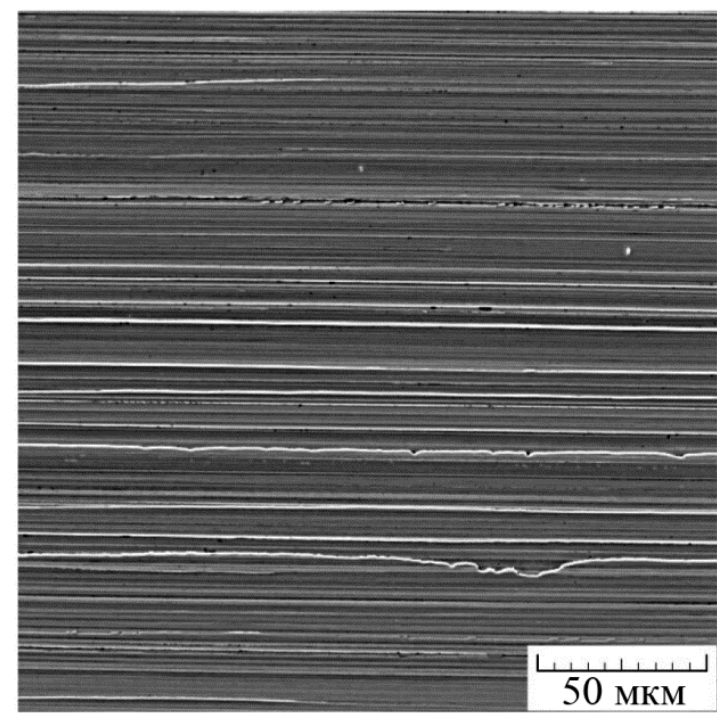

$a$

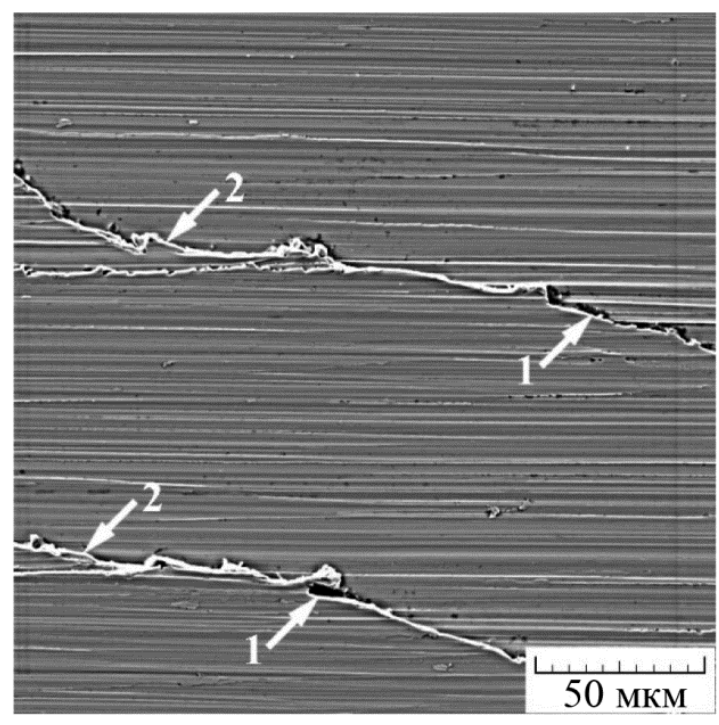

B

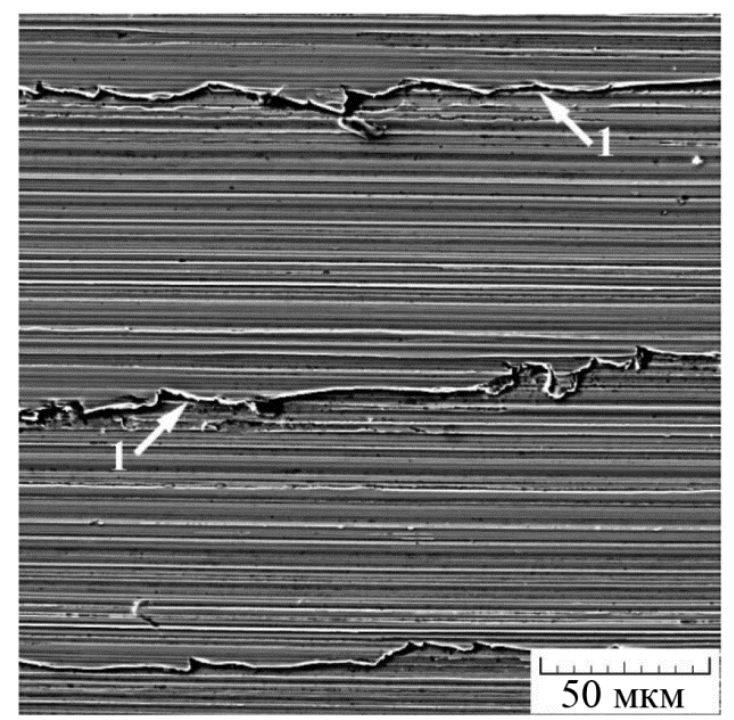

$\sigma$

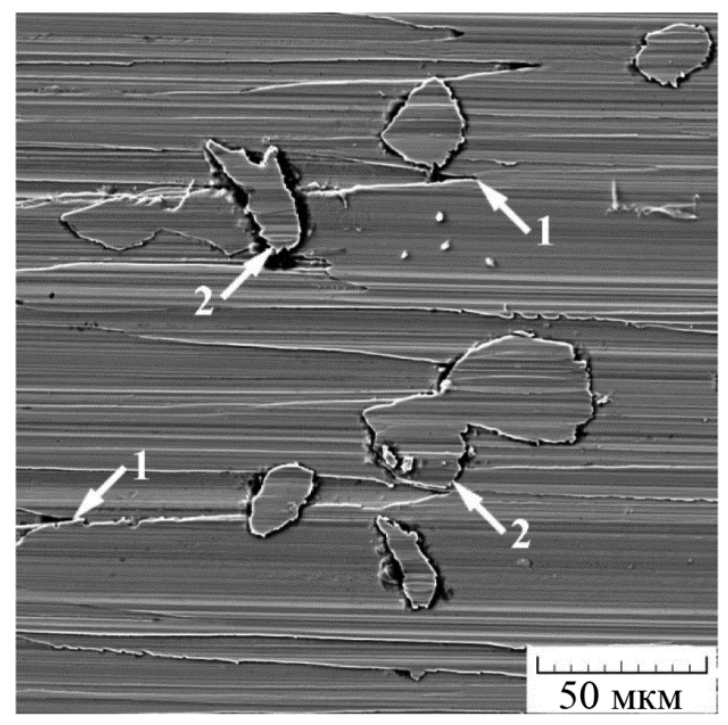

2

Рис. 4. Вид поверхности (электронная сканирующая микроскопия) после фрикционной обработки стали AISI 321 с числом двойных проходов индентора $p=14(a) ; 48$ (б); 112 (в) и 160 (2). Стрелками 1 указаны трещины, стрелками 2 - участки поверхности со следами выкрашивания 


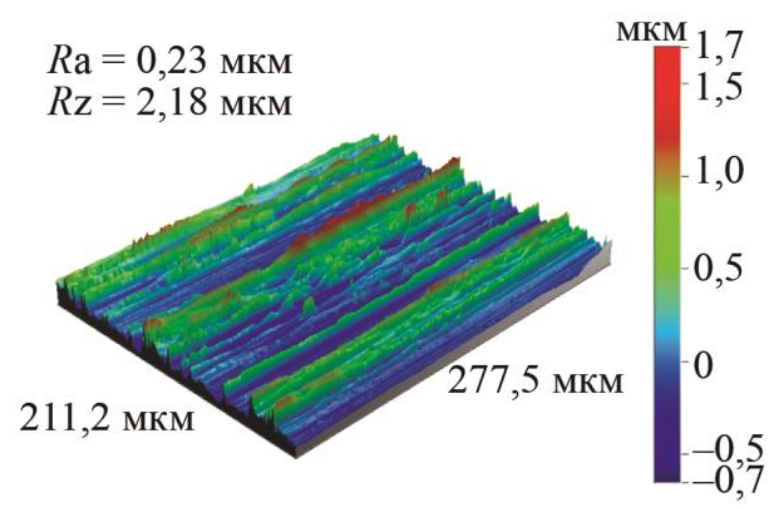

$a$

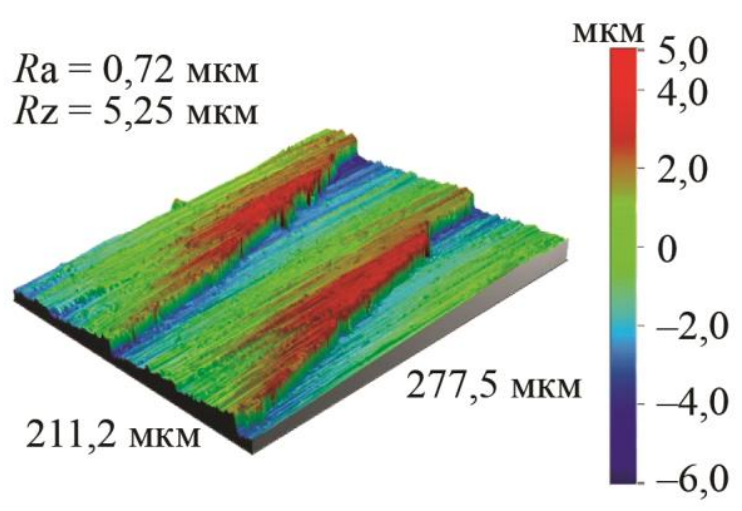

B

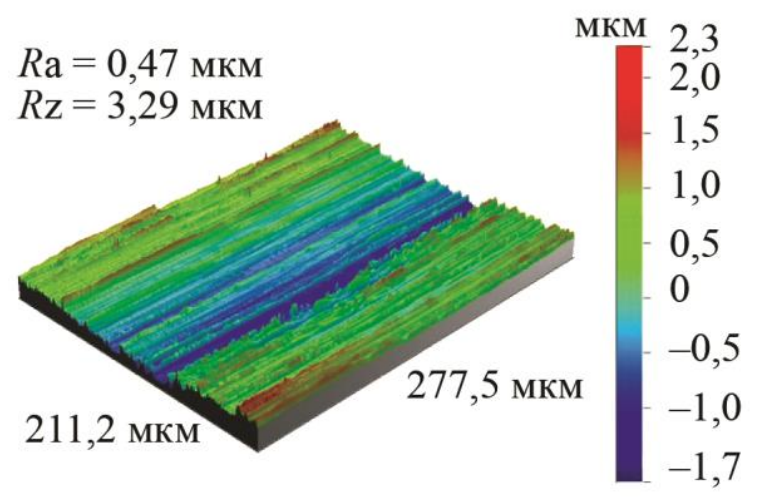

$\sigma$

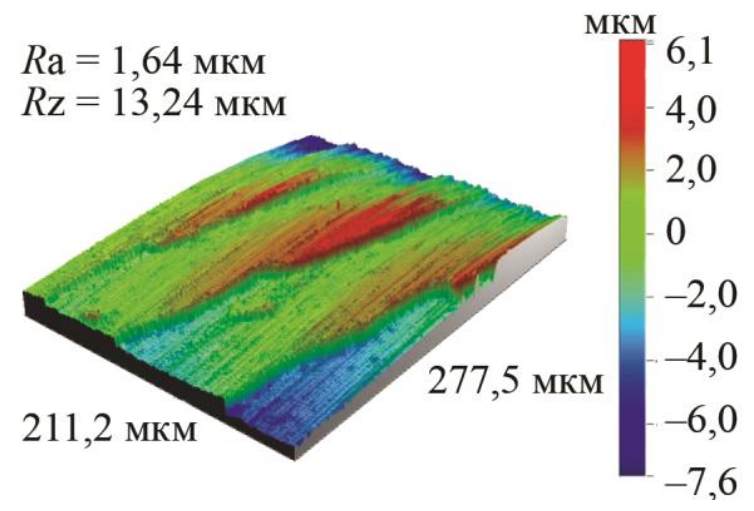

2

Рис. 5. Вид поверхности (оптическая профилометрия)

после фрикционной обработки стали AISI 321 с числом двойных проходов индентора $p=14(a) ; 48(б) ; 112$ (в) и 160 (2)

Таким образом, результаты дюрометрического и рентгеноструктурного анализа и свидетельствуют об упрочнении стали AISI 321 при фрикционной обработке. При этом фрикционная обработка с числом двойных проходов индентора 14, когда разрушения поверхности еще не происходит, существенно (в 3,7 раза) повышает микротвердость стали AISI 321 до $730 \mathrm{HV} 0,025$.

В табл. 2 и на рис. 7 и 8 приведены данные кинетического индентирования, из которых следует, что в результате фрикционной обработки стали AISI 321 при увеличении числа двойных проходов индентора происходит уменьшение значений максимальной и остаточной глубины вдавливания индентора $h_{\max }$ и $h_{\mathrm{p}}$, рост твердости по Мартенсу НМ, которая учитывает не только пластическую, но и упругую деформации и твердости вдавливания при максимальной нагрузке $H_{\text {IT. }}$. Наблюдается также рост работы обратной упругой деформации вдавливания $W_{\mathrm{e}}$. Величина $W_{\mathrm{e}}$ зависит от отношения твердости к модулю упругости материала: чем выше это отношение, тем большая работа затрачивается на упругую деформацию и тем большая энергия упругой деформации высвобождается при снятии измерительной нагрузки [32]. Общая механическая работа вдавливания $W_{t}$, которая состоит из работы пластической деформации и работы упругого восстановления, после фрикционной обработки, напротив, снижается (табл. 2), поскольку упрочненный с помощью фрикционной обработки поверхностный слой обладает меньшей пластичностью, чем металл, подвергнутый термической обработке, и, соответственно, меньше деформируется при микроиндентировании. Отметим, что фрикционная обработка привела к росту модуля контактной упругости $E^{*}$ стали (табл. 2). Известно, что модули упругости металлов и сплавов являются, за редким исключе- 
нием (например [33, 34]), структурно малочувствительными свойствами. В работе [33] при циклическом растяжении углеродистой перлитной стали наблюдали снижение величины модуля упругости, обусловленное уменьшением содержания углерода в ферритной составляющей перлита. В работе [34] при исследовании модуля упругости поликристаллического железа после механических испытаний на растяжение был установлен некоторый рост модуля упругости при больших деформациях, обусловленный формированием ячеистой дислокационной структуры. Следовательно, наблюдаемое изменение модуля контактной упругости $E^{*}$ стали AISI 321 может быть обусловлено изменением структурно-фазового состояния и, в частности, плотности дислокаций и типа дислокационной структуры, формирующейся при фрикционной обработке.

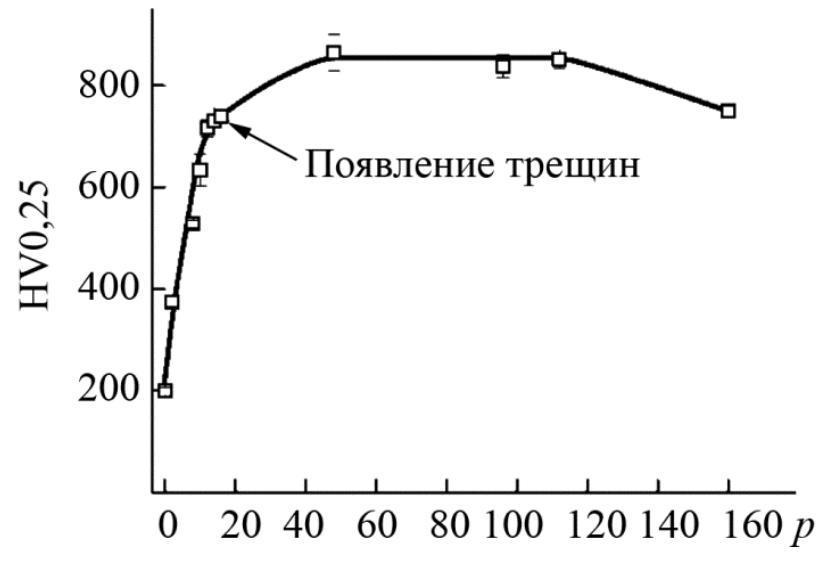

$a$

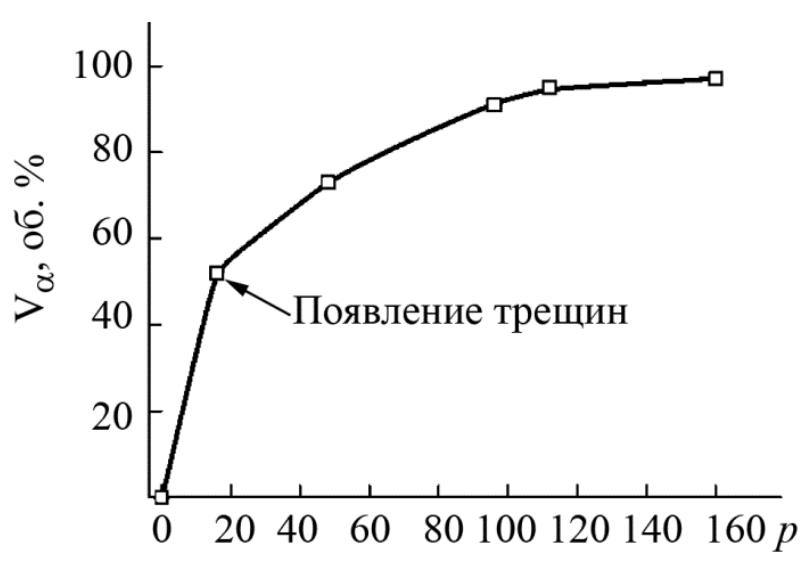

$\sigma$

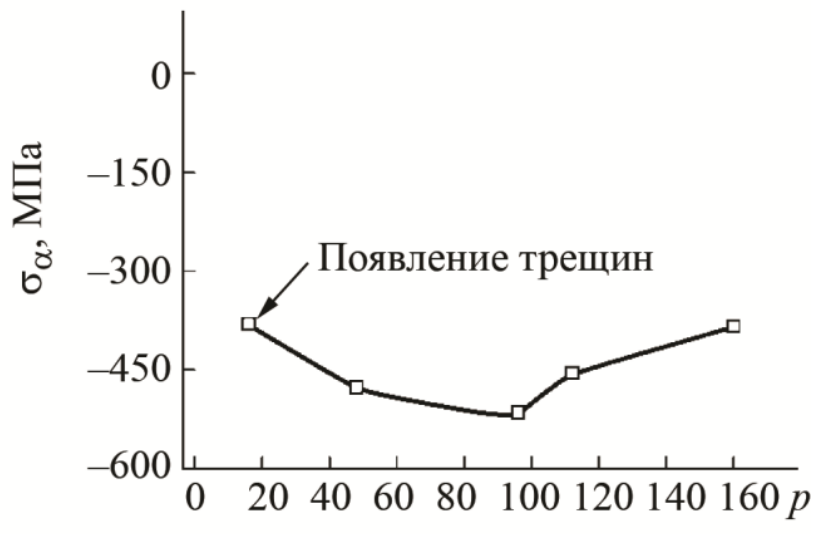

B

Рис. 6. Влияние числа двойных проходов индентора р при фрикционной обработке на микротвердость $\mathrm{HV} 0,025$ (a), количество мартенсита деформации $\mathrm{V}_{\alpha}($ б) и остаточные напряжения в $\alpha$-фазе $\sigma_{\alpha}($ в) в поверхностном слое стали AISI 321 


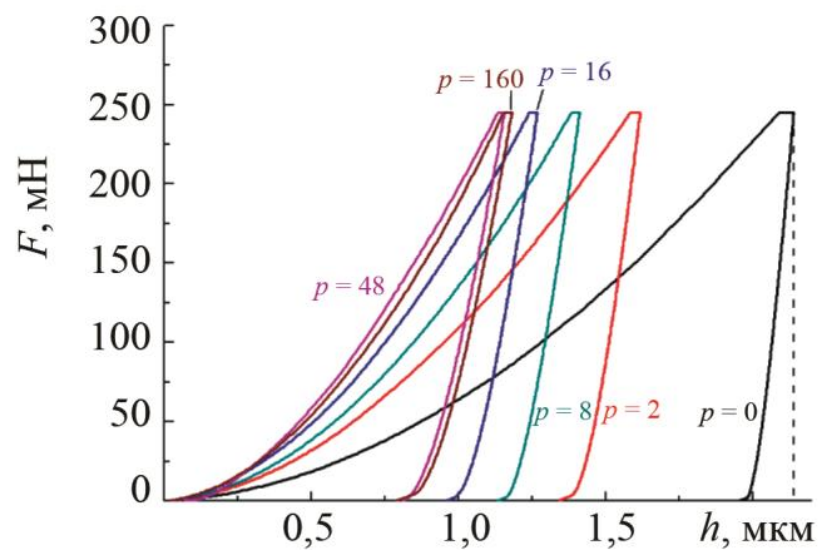

Рис. 7. Кривые нагружения при кинетическом микроиндентировании стали AISI 321 после фрикционной обработки с различным числом двойных проходов индентора $p$

Таблица 2 - Результаты микроиндентирования при максимальной нагрузке на индентор 0,245 Н образцов из стали AISI 321 без обработки и после фрикционной обработки с различным числом двойных проходов индентора $\mathrm{p}$

\begin{tabular}{|c|c|c|c|c|c|c|c|c|}
\hline $\begin{array}{c}\text { Число } \\
\text { двойных } \\
\text { проходов } \\
\begin{array}{c}\text { инден- } \\
\text { тора } \mathrm{p}\end{array}\end{array}$ & $\begin{array}{c}h_{\text {max }}, \\
\text { мкм }\end{array}$ & $\begin{array}{c}h_{\mathrm{p}}, \\
\text { мкм }\end{array}$ & $\begin{array}{c}h_{1}, \\
\text { мкм }\end{array}$ & $\begin{array}{c}\mathrm{HM}, \\
\text { ГПа }\end{array}$ & $\begin{array}{c}H_{\mathrm{IT}}, \\
\text { ГПа }\end{array}$ & $\begin{array}{c}E^{*}, \\
\text { ГПа }\end{array}$ & $\begin{array}{c}W_{\mathrm{e},} \\
\text { нДж }\end{array}$ & $\begin{array}{c}W_{\mathrm{t}}, \\
\text { нДж }\end{array}$ \\
$\begin{array}{c}\text { 0 (без } \\
\text { Обработ- } \\
\text { ки) }\end{array}$ & $2,15 \pm 0,04$ & $2,06 \pm 0,05$ & $2,10 \pm 0,04$ & $1,9 \pm 0,1$ & $2,2 \pm 0,1$ & $188 \pm 6$ & $16,8 \pm 0,5$ & $186 \pm 4$ \\
\hline 2 & $1,62 \pm 0,02$ & $1,45 \pm 0,03$ & $1,58 \pm 0,03$ & $3,3 \pm 0,1$ & $4,0 \pm 0,1$ & $187 \pm 5$ & $23,1 \pm 0,4$ & $141 \pm 3$ \\
\hline 8 & $1,42 \pm 0,02$ & $1,23 \pm 0,03$ & $1,39 \pm 0,02$ & $4,2 \pm 0,1$ & $5,4 \pm 0,2$ & $190 \pm 3$ & $26,2 \pm 0,5$ & $125 \pm 2$ \\
\hline 10 & $1,37 \pm 0,02$ & $1,16 \pm 0,03$ & $1,33 \pm 0,03$ & $4,6 \pm 0,2$ & $6,0 \pm 0,2$ & $194 \pm 5$ & $27,3 \pm 0,5$ & $120 \pm 2$ \\
\hline 12 & $1,29 \pm 0,04$ & $1,07 \pm 0,04$ & $1,26 \pm 0,05$ & $5,1 \pm 0,3$ & $6,8 \pm 0,5$ & $190 \pm 6$ & $29,8 \pm 0,4$ & $117 \pm 4$ \\
\hline 14 & $1,24 \pm 0,02$ & $1,04 \pm 0,02$ & $1,21 \pm 0,02$ & $5,5 \pm 0,2$ & $7,3 \pm 0,2$ & $209 \pm 8$ & $28,4 \pm 0,8$ & $112 \pm 4$ \\
\hline 16 & $1,27 \pm 0,04$ & $1,05 \pm 0,04$ & $1,24 \pm 0,04$ & $5,2 \pm 0,3$ & $7,0 \pm 0,4$ & $201 \pm 9$ & $28,9 \pm 0,5$ & $112 \pm 3$ \\
\hline 48 & $1,16 \pm 0,04$ & $0,89 \pm 0,03$ & $1,14 \pm 0,04$ & $6,2 \pm 0,4$ & $8,8 \pm 0,6$ & $205 \pm 9$ & $32,4 \pm 0,6$ & $102 \pm 5$ \\
\hline 96 & $1,15 \pm 0,05$ & $0,86 \pm 0,04$ & $1,13 \pm 0,05$ & $6,3 \pm 0,5$ & $8,7 \pm 0,8$ & $224 \pm 13$ & $30,0 \pm 0,3$ & $99 \pm 3$ \\
\hline 112 & $1,15 \pm 0,02$ & $0,89 \pm 0,01$ & $1,12 \pm 0,02$ & $6,3 \pm 0,2$ & $8,8 \pm 0,3$ & $219 \pm 10$ & $30,6 \pm 1,0$ & $98 \pm 4$ \\
\hline 160 & $1,17 \pm 0,04$ & $0,89 \pm 0,04$ & $1,15 \pm 0,04$ & $6,1 \pm 0,4$ & $8,4 \pm 0,6$ & $206 \pm 15$ & $31,9 \pm 1,1$ & $99 \pm 7$ \\
\hline
\end{tabular}

На основе измеряемых при индентировании характеристик определяли также параметры, по которым оценивают способность поверхностных слоев различных материалов сопротивляться механическому контактному воздействию и, соответственно, выдерживать эксплуатационные нагрузки. Так, отношение твердости вдавливания к контактному модулю упругости $H_{\mathrm{IT}} / E^{*}$ (удельная контактная твердость) [35] и упругое восстановление $R_{\mathrm{e}}=\left(\left(h_{\max }-h_{\mathrm{p}}\right) / h_{\max }\right) \times 100 \%$ [36] характеризуют упругую деформацию (долю упругой деформации в общей деформации) и, соответSavrai R.A. et al. / Improving the strength of the AISI 321 austenitic stainless steel 
ственно, способность материала сопротивляться нагружению без пластического деформирования. Отношение $H^{3} / E^{* 2}$ принято считать качественной сравнительной характеристикой сопротивления пластической деформации, поскольку напряжение течения пропорционально указанному отношению $\left(P_{\text {у }} \sim H^{3} / E^{* 2}\right)$ [37]. Чем выше значения указанных параметров, тем выше способность материала выдерживать более высокие контактные нагрузки до начала пластического деформирования и сопротивляться разрушению при контактных нагрузках.

Показатель пластичности $\delta_{\mathrm{A}}\left(\delta_{\mathrm{A}}=\left(W_{\text {о.ф. }} / W_{\mathrm{t}}\right)\right.$, где $W_{\text {о.ф. }}-$ работа остаточного формоизменения (рис. 2)) характеризует пластичность материалов долей пластической деформации в общей упругопластической деформации. Чем выше значения данного параметра, тем выше пластичность материала. При этом показано, что для пластичных при растяжении материалов $\delta_{\mathrm{A}} \geq 0,9$ [38].

Ползучесть $C_{\text {Iт }}\left(C_{\mathrm{IT}}=\left(\left(h_{\max }-h_{1)} / h_{1}\right) \times 100 \%\right.\right.$, где $h_{1}-$ глубина внедрения индентора, соответствующая начальной точке горизонтального участка на кривой нагружения (рис. 2)) характеризует способность материала к формоизменению при постоянно действующей нагрузке. Чем ниже значения данного параметра, тем ниже ползучесть материала.

Таблица 3 - Упругое восстановление $R_{\mathrm{e}}$, отношения $H_{\mathrm{IT}} / E^{*}, H_{\mathrm{IT}}^{3} / E^{* 2}$, пластичность $\delta_{\mathrm{A}}$ и ползучесть $C_{\text {IT }}$ образцов из стали AISI 321 без обработки и после фрикционной обработки с различным числом двойных проходов индентора $p$

\begin{tabular}{|c|c|c|c|c|c|}
\hline $\begin{array}{c}\text { Число } \\
\text { двойных проходов } \\
\text { индентора } p\end{array}$ & $R_{\mathrm{e}}, \%$ & $H_{\mathrm{IT}} / E^{*}$ & $H_{\mathrm{IT}}^{3} / E^{* 2}, \Gamma П а$ & $\delta_{\mathrm{A}}$ & $C_{\mathrm{IT}}, \%$ \\
\hline 0 (без обработки) & 4,2 & 0,012 & 0,0003 & 0,91 & 2,38 \\
\hline 2 & 10,5 & 0,021 & 0,0018 & 0,84 & 2,53 \\
\hline 8 & 13,4 & 0,028 & 0,0044 & 0,79 & 2,16 \\
\hline 10 & 15,3 & 0,031 & 0,0057 & 0,77 & 3,01 \\
\hline 12 & 17,1 & 0,036 & 0,0087 & 0,75 & 2,38 \\
\hline 14 & 16,1 & 0,035 & 0,0089 & 0,75 & 2,48 \\
\hline 16 & 17,3 & 0,035 & 0,0085 & 0,74 & 2,42 \\
\hline 48 & 23,3 & 0,043 & 0,0162 & 0,68 & 1,75 \\
\hline 96 & 25,2 & 0,039 & 0,0131 & 0,70 & 1,77 \\
\hline 112 & 22,6 & 0,040 & 0,0142 & 0,69 & 2,68 \\
\hline 160 & 23,9 & 0,041 & 0,0140 & 0,68 & 1,74 \\
\hline
\end{tabular}

Из данных табл. 3 и рис. 8 следует, что после фрикционной обработки параметры $R_{\mathrm{e}}$, $H_{\mathrm{IT}} / E^{*}$ и $H_{\mathrm{IT}}^{3} / E^{* 2}$ стали AISI 321 значительно возрастают (рис. $8 a-8$ ). Следовательно, фрикционная обработка стали AISI 321 повышает стойкость поверхности в условиях интенсивного контактного взаимодействия. При этом пластичность $\delta_{\mathrm{A}}$ снижается (рис. 8 2), что усиливает склонность упрочненной поверхности к трещинообразованию.

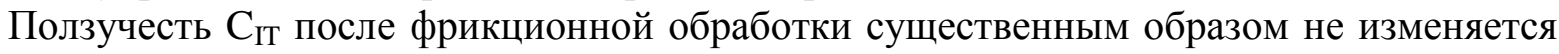
и в среднем составляет $2,3 \%$, хотя при фрикционной обработке с числом двойных проходов индентора 48 и более наблюдается тенденция к некоторому снижению ползучести (рис. $8 \partial$ ). Это может быть обусловлено достаточно малой толщиной упрочненного поверхностного слоя, формируемого фрикционной обработкой. Поэтому при данных условиях индентирования ползучесть определяется преимущественно свойствами нижележащих слоев. 


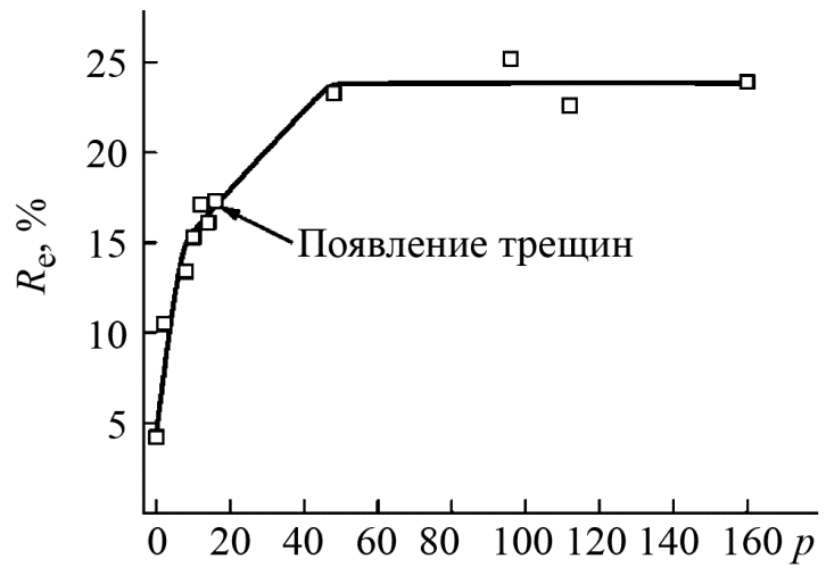

$a$

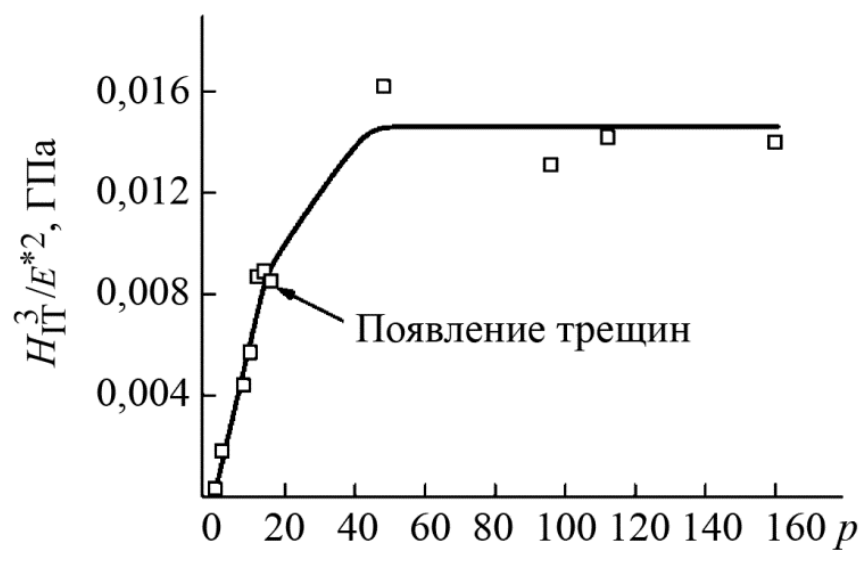

B

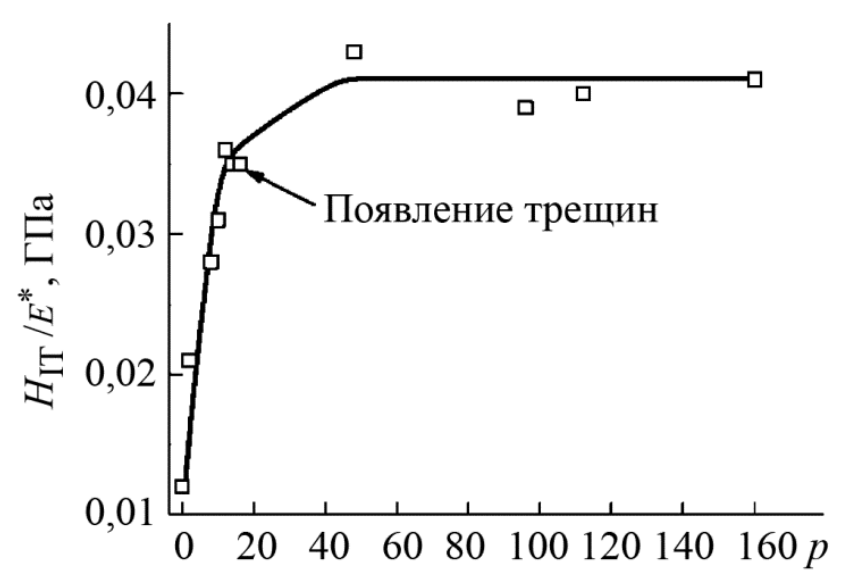

$\sigma$

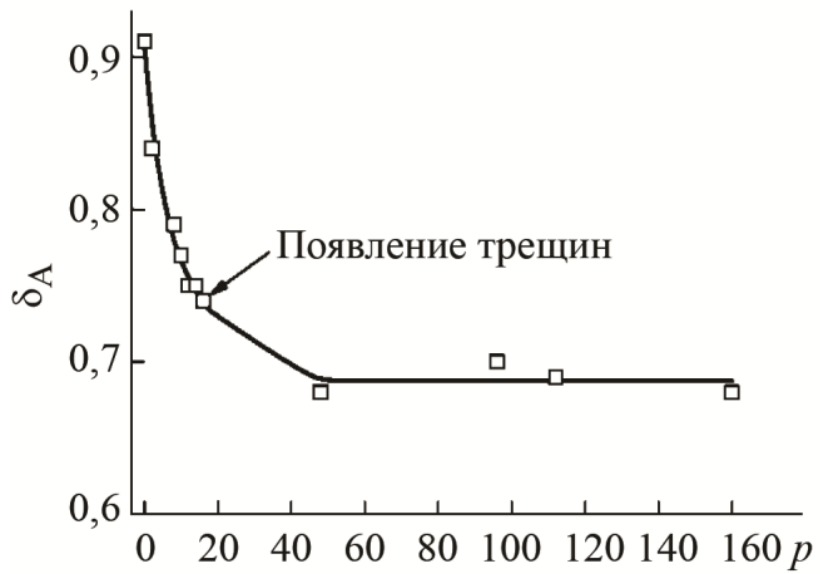
2

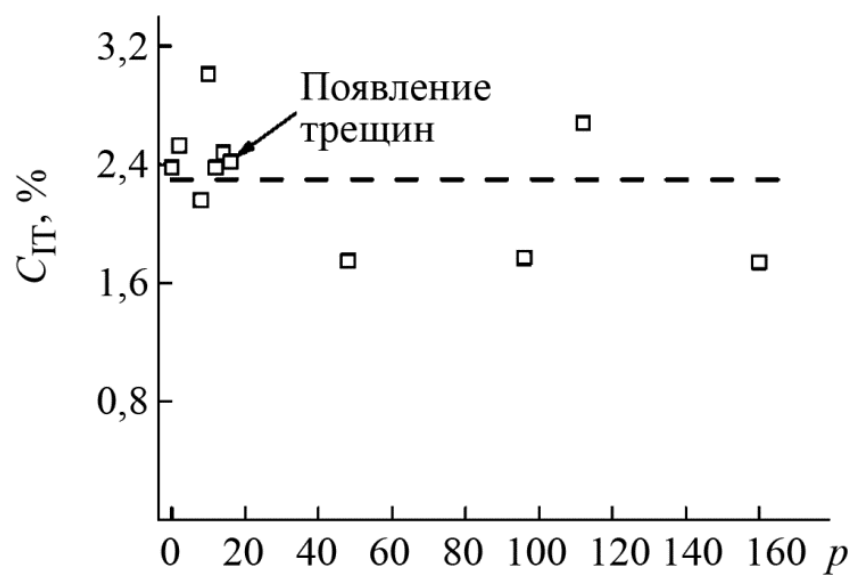

$\partial$

Рис. 8. Влияние числа двойных проходов индентора р при фрикционной обработке на упругое восстановление $R_{\mathrm{e}}(a)$, отношения $H_{\mathrm{IT}} / E^{*}(б), H_{\mathrm{IT}}^{3} / E^{* 2}(b)$, пластичность $\delta_{\mathrm{A}}(2)$ и ползучесть $C_{\mathrm{IT}}(\partial)$ образцов из стали AISI 321

Таким образом, данные кинетического микроиндентирования согласуются с результатами металлографического, дюрометрического и рентгеноструктурного анализа и свидетельствуют об упрочнении и повышении стойкости поверхности в условиях интенсивного контактного взаимодействия стали AISI 321 в результате фрикционной обработки. При этом 
фрикционная обработка с числом двойных проходов индентора 14, когда разрушения поверхности еще не происходит, значительно повышает способность поверхности сопротивляться механическому контактному воздействию, о чем свидетельствует рост параметров $R_{\mathrm{e}}$ в 3,9 раза, $H_{\mathrm{IT}} / E^{*}$ в 3 раза и $H_{\mathrm{IT}}^{3} / E^{* 2}$ в 29,6 раза. Следует также отметить, что, используя сочетание определяемых при кинетическом микроиндентировании характеристик прочности и пластичности, можно подобрать наилучшие параметры фрикционной обработки с точки зрения заданных условий эксплуатации.

\section{4. Заключение}

Исследовано влияние фрикционной обработки полусферическим индентором из синтетиче-ского алмаза в безокислительной среде аргона и нагрузке на индентор 294 Н с различным числом проходов индентора на микромеханические характеристики, фазовый состав, остаточные напряжения, шероховатость и поврежденность поверхностного слоя коррозионностойкой аустенитной стали AISI 321.

Установлено, что при увеличении числа двойных проходов индентора от 2 до 14 не наблюдается признаков разрушения поверхности стали AISI 321. Процесс разрушения обработанной поверхности начинается при 16 двойных проходах, когда появляются отдельные трещины. Дальнейшее увеличение числа двойных проходов до 48 и более приводит к росту количества и протяженности трещин с последующим выкрашиванием участков поверхности и формированием характерных ступенек. Разрушение поверхности также сопровождается ростом коэффициента трения от 0,39 до 0,52 и шероховатости поверхности от $R \mathrm{a}=0,23$ мкм, $R \mathrm{z}=2,18$ мкм при 14 двойных проходах индентора до $R \mathrm{a}=1,64$ мкм, $R \mathrm{z}=13,24$ мкм при 160 двойных проходах.

В процессе фрикционной обработки стали AISI 321 происходит непрерывное увеличение содержания мартенсита деформации, которое достигает 97 \% при 160 двойных проходах индентора. При этом в поверхностном слое формируются сжимающие остаточные напряжения.

Фрикционная обработка стали AISI 321 приводит к значительному упрочнению поверхностного слоя уже на начальных этапах нагружения. При этом фрикционная обработка с числом двойных проходов индентора 14, когда разрушения поверхности еще не происходит, повышает микротвердость стали AISI 321 в 3,7 раза от 200 до $730 \mathrm{HV0,025.} \mathrm{Максимального}$ значения, равного 865 HV0,025, микротвердость достигает при 48 двойных проходах, однако при такой обработке качество поверхности заметно снижается.

Результаты кинетического микроиндентирования также свидетельствуют об упрочнении и повышении стойкости поверхности в условиях интенсивного контактного взаимодействия стали AISI 321 в результате фрикционной обработки. При этом фрикционная обработка с числом двойных проходов индентора 14, когда не наблюдается разрушения поверхности, значительно повышает способность поверхности сопротивляться механическому контактному воздействию.

Таким образом, для обеспечения существенного упрочнения, высокого качества поверхности и стойкости при контактных нагрузках, фрикционную обработку стали AISI 321 при использованных технологических параметрах целесообразно проводить с числом двойных проходов не более 14.

\section{Благодарность}

Работа выполнена в рамках Комплексной программы УрО РАН (проект № 15-10-1-22) и в рамках государственного задания ФАНО России по теме «Структура» № 01201463331 при частичной поддержке гранта РФФИ 15-08-06754_a.

Электронная сканирующая микроскопия, профилометрия и микромеханические испытания выполнены в ЦКП «Пластометрия» ИМАШ УрО РАН. 


\section{Литература}

1. Sun Y. Sliding wear behavior of surface mechanical attrition treated AISI 304 stainless steel // Tribology International. - 2013. - Vol. 57. - P. 67-75. - DOI: 10.1016/j.triboint.2012.07.015

2. Influence of peening on corrosion properties of AISI 304 stainless steel / H. Lee, D. Kim, J. Jung, Y. Pyoun, K. Shin // Corrosion science. - 2009. - Vol. 51, iss. 12. - P. 2826-2830. DOI: 10.1016/j.corsci.2009.08.008

3. Mordyuk B. N., Prokopenko G. I. Ultrasonic impact peening for the surface properties' management // Journal of Sound and Vibration. - 2007. - Vol. 308, iss. 3-5. - P. 855-866. DOI: 10.1016/j.jsv.2007.03.054

4. Baraz V. P., Kartak B. P., Mineeva O. N. Special features of friction hardening of austenitic steel with unstable gamma-phase // Metal Science and Heat Treatment. - 2011. - Vol. 52, iss. 9-10. P. 473-475. - DOI: 10.1007/s11041-010-9302-X

5. Improvement in cavitation erosion resistance of AISI 316L stainless steel by friction stir processing / M. Hajian, A. Abdollah-zadeh, S. S. Rezaei-Nejad, H. Assadi, S. M. M. Hadavi, K. Chung, M. Shokouhimehr // Applied Surface Science. - 2014. - Vol. 308. - P. 184-192. DOI: $10.1016 /$ j.apsusc.2014.04.132

6. Advance Complex Liquid Nitriding of Stainless Steel AISI 321 Surface at $430{ }^{\circ} \mathrm{C} / \mathrm{Y}$. Lin, J. Wang, D. Zeng, R. Huang, H. Fan // Journal of Materials Engineering and Performance. - 2013. Vol. 22, no. 9. - P. 2567-2573. - DOI: 10.1007/s11665-013-0545-8

7. Laser Surface Hardening of Austenitic Stainless Steel / S. M. Levcovici, D. T. Levcovici, V. Munteanu, M. M. Paraschiv, A. Preda // Journal of Materials Engineering and Performance. 2000. - Vol. 9, no. 5. - P. 536-540. - DOI: 10.1361/105994900770345665

8. Effect of nanostructured grains on martensite formation during plasma nitriding of AISI 321 austenitic stainless steel / M. Golzar Shahri, M. Salehi, S. R. Hosseini, M. Naderi // Surface and Coatings Technology. - 2017. - Vol. 310. - P. 231-238. - DOI:10.1016/j.surfcoat.2016.12.019

9. Макаров А. В. Наноструктурирующая фрикционная обработка углеродистых и низколегированных сталей / T. IV : Перспективные материалы : учебное пособие / под ред. Д. Л. Мерсона. - Тольятти : ТГУ, 2011. - 434 с. - Гл. 3. - С. 123-208.

10. Повышение трибологических свойств аустенитной стали $12 \mathrm{X} 18 \mathrm{H} 10 \mathrm{~T}$ наноструктурирующей фрикционной обработкой / А. В. Макаров, П. А. Скорынина, А. Л. Осинцева, А. С. Юровских, Р. А. Саврай // Обработка металлов: технология, оборудование, инструменты. - 2015. - № 4 (69). - С. 80-92.

11. Makarov A. V., Korshunov L. G. Strength and wear resistance of nanocrystal structures on friction surfaces of steels with martensitic base // Russian Physics Journal. - 2004. - Vol. 47, no. 8. - P. 857-871. - DOI: 10.1007/s11182-005-0005-5

12. Sliding friction surface microstructure and wear resistance of 9SiCr steel with lowtemperature austempering treatment / T. S. Wang, J. Yang, C. J. Shang, X. Y. Li, B. Lv, M. Zhang, F. C. Zhang // Surface and Coatings Technology. - 2008. - Vol. 202, iss. 16. - P. 4036-4040. DOI: $10.1016 /$ j.surfcoat.2008.02.013

13. Role of strain gradient on the formation of nanocrystalline structure produced by severe plastic deformation / J. G. Li, M. Umemoto, Y. Todaka, K. Tsuchiya // Journal of Alloys and Compounds. - 2007. - Vol. 434-435. - P. 290-293. - DOI: 10.1016/j.jallcom.2006.08.167

14. Effect of hardening friction treatment with hard-alloy indenter on microstructure, mechanical properties, and deformation and fracture features of constructional steel under static and cyclic tension / A. V. Makarov, R. A. Savrai, N. A. Pozdejeva, S. V. Smirnov, D. I. Vichuzhanin, L. G. Korshunov, I. Yu. Malygina // Surface and Coatings Technology. - 2010. - Vol. 205, iss. 3. P. 841-852. - DOI: 10.1016/j.surfcoat.2010.08.025

15. Stress and strain and damage during frictional strengthening treatment of flat steel surface with a sliding cylindrical indenter / D. I. Vychuzhanin, A. V. Makarov, S. V. Smirnov, 
N. A. Pozdeeva, I. Y. Malygina // Journal of Machinery Manufacture and Reliability. - 2011. Vol. 40, iss. 6. - P. 554-560. - DOI: 10.3103/S1052618811050190

16. Трибологические аспекты наноструктурирующего выглаживания конструкционных сталей / В. П. Кузнецов, А. В. Макаров, С. Г. Псахье, Р. А. Саврай, И. Ю. Малыгина, Н. А. Давыдова // Физическая мезомеханика. - 2014. - Т. 17, № 3. - С. 14-30.

17. Effect of the Technological Conditions of Frictional Treatment on the Structure, Phase Composition and Hardening of Metastable Austenitic Steel / A. V. Makarov, P. A. Skorynina, A. S. Yurovskikh, A. L. Osintseva // AIP Conference Proceedings. - 2016. - Vol. 1785, no. 040035. - DOI: 10.1063/1.4967092

18. Wang T., Yu J., Dong B. Surface nanocrystallization induced by shot peening and its effect on corrosion resistance of 1Cr18Ni9Ti stainless steel // Surface and Coatings Technology. - 2006. Vol. 200. - P. 4777-4781. - DOI: 10.1016/j.surfcoat.2005.04.046

19. Pugacheva N. B., Michurov N. S., Bykova T. M. structure and properties of the Al/SiC composite material // The Physics of Metals and Metallography. - 2016. - Vol. 117, no. 6. P. 634-640. - DOI: 10.1134/S0031918X16060119

20. Structure and thermophysical properties of aluminum-matrix composites. The Physics of Metals and Metallography / N. B. Pugacheva, N. S. Michurov, E. I. Senaeva, T. M. Bykova. 2016. - Vol. 117, no. 11. - P. 1144-1151. - DOI: 10.1134/S0031918X16110119

21. The Behavior of Gas Powder Laser Clad NiCrBSi Coatings Under Contact Loading / R. A. Savrai, A. V. Makarov, N. N. Soboleva, I. Yu. Malygina, A. L. Osintseva // Journal of Materials Engineering and Performance. - 2016. - Vol. 25, iss.3. - P. 1068-1075. DOI: $10.1007 / \mathrm{s} 11665-016-1925-7$

22. Pugacheva N. B., Trushina E. B., Bykova T. M. Research on the tribological properties of iron borides as diffusion coatings // Journal of Friction and Wear. - 2014. - Vol. 35, no. 6. P. 489-496. - DOI: 10.3103/S1068366614060117

23. Пугачева Н. Б., Быкова Т. М., Трушина Е. Б. Влияние состава стали-основы на структуру и свойства диффузионных боридных покрытий // Упрочняющие технологии и покрытия. - 2013. - № 4. - С. 3-7.

24. Structure, mechanical characteristics, and deformation and fracture features of quenched structural steel under static and cyclic loading after combined strain-heat nanostructuring treatment / A. V. Makarov, R. A. Savrai, E. S. Gorkunov, A. S. Yurovskikh, I. Yu. Malygina, N. A. Davydova // Physical Mesomechanics. - 2015. - Vol. 18, iss. 1. - P. 43-57. - DOI: 10.1134/S1029959915010063

25. Повышение микромеханических свойств и износостойкости хромоникелевого лазерного покрытия финишной фрикционной обработкой / А. В. Макаров, Н. Н. Соболева, Р. А. Саврай, И. Ю. Малыгина // Вектор науки ТГУ. - 2015. - № 4 (34). - С. 60-67. DOI: 10.18323/2073-5073-2015-4-60-67

26. Структурная неоднородность сварного соединения алюминиевого сплава и моделирование его упругой деформации / С. В. Смирнов, Н. Б. Пугачева, М. В. Мясникова, Е. О. Смирнова // Физическая мезомеханика. - 2014. - № 1. - С. 51-56.

27. Смирнов С. В., Пугачева Н. Б., Мясникова М. В. Определение предельных деформаций до разрушения зон диффузионных алюминидных покрытий // Деформация и разрушение материалов. - 2014. - № 12. - С. 17-22.

28. Pugacheva N. B., Myasnikova M. V., Michurov N. S. Simulation of the elastic deformation of laser-welded joints of an austenitic corrosion-resistant steel and a titanium alloy with an intermediate copper insert // The Physics of Metals and Metallography. - 2016. - Vol. 117, no. 2. P. 195-203. - DOI: 10.7868/S0015323015120074

29. Способ обработки стальных изделий : пат. №2194773 Рос. Федерация / Макаров А. В., Коршунов Л. Г., Осинцева А. Л., БИМП. - 2002. - № 35.

30. Русаков А. А. Рентгенография металлов. - М : Атомиздат, 1977. - 480 с. 
31. ГОСТ Р 8.748-2011 (ИСО 14577-1:2002). Государственная система обеспечения единства измерений (ГСИ). Металлы и сплавы. Измерение твердости и других характеристик материалов при инструментальном индентировании. - Ч. 1. Метод испытаний.

32. Oliver W. C., Pharr J. M. An improved technique for determining hardness and elastic modulus using load and displacement sensing indentation experiments // Journal of Materials Research. - 1992. - Vol. 7, no. 6. - P. 1564-1583. - DOI:10.1557/JMR.1992.1564

33. Structural features of the behavior of a high-carbon pearlitic steel upon cyclic loading / A. V. Makarov, R. A. Savrai, V. M. Schastlivtsev, T. I. Tabatchikova, I. L. Yakovleva, L. Yu. Egorova // The Physics of Metals and Metallography. - 2011. - Vol. 111, iss. 1. - P. 95-109. DOI: V10.1134/S0031918X11010091

34. Change of Young's modulus of cold-deformed pure iron in a tensile test / J. A. Benito, J. Jorba, J. M. Manero, A. Roca // Metallurgical and Materials Transactions A. - 2005. - Vol. 36, iss. 12. - P. 3317-3324. - DOI: 10.1007/s11661-005-0006-6

35. Cheng Y. T., Cheng C. M. Relationships between hardness, elastic modulus and the work of indentation // Applied Physics Letters. - 1998. - Vol. 73, no. 5. - P. 614-618. DOI: $10.1063 / 1.121873$

36. Page T. F., Hainsworth S. V. Using nanoindentation techniques for the characterization of coated systems: a critique // Surface and Coatings Technology. - 1993. - Vol. 61, iss. 1-3. P. 201-208. - DOI: 10.1016/0257-8972(93)90226-E

37. Mayrhofer P. H., Mitterer C., Musil J. Structure-property relationships in single- and dualphase nanocrystalline hard coatings // Surface and Coatings Technology. - 2003. - Vol. 174-175. P. 725-731. - DOI: 10.1016/S0257-8972(03)00576-0

38. Мильман Ю. В., Чугунова С. И., Гончарова И. В. Характеристика пластичности, определяемая методом индентирования // Вопросы атомной науки и техники. - 2011. - № 4. C. $182-187$. 